\title{
Properties of material with nanofiber layer used for filtering the inlet air of internal combustion engines
}

\begin{abstract}
Nanofiber properties, and the possibilities of their application in industry, including the production of car air intake filtration materials for vehicle engines are discussed. The attention is paid to the low efficiency of standard filtration materials based on cellulose in the range of dust grains below $5 \mu \mathrm{m}$. The properties of filtration materials with nanofibers addition are described. The conditions, and methodology of material filter paper tests at the station with particle counter were developed. Studies on the filtration characteristics, such as: efficiency, accuracy, as well as pressure drop of filtration materials differing in structure were made: standard paper, cellulose, and these materials with the addition of nanofibers. These are commonly used filter materials for filter inserts production of car air intake systems. Test results show significantly higher values of the efficiency, and filtration accuracy of materials with nanofiber layer addition of dust grains below $5 \mu \mathrm{m}$ in comparison with standard filter paper. It was found that there are $16 \mu \mathrm{m}$ dust grains in the air flow behind the insert made out of cellulose,, which may be the reason for the accelerated wear of the engine's "piston-piston ring-cylinder" association. Lower values of dust mass loading coefficient $\mathrm{km}$ for filtration materials with the addition of nanofiber layer, in relation to standard filter paper were observed.
\end{abstract}

Key words: engine, air filter, filtration materials, nanofiber filter media, filtration efficiency, filtration performance, pressure drop, dust mass loading

\section{Introduction}

The dominant filter material of modern inlet air internal combustion engines is filter paper (porous material), characterized by filtration performance $\mathrm{d}_{\mathrm{z}} \geq 5 \mu \mathrm{m}$, filtration efficiency at $\varphi_{\mathrm{w}}=99.9 \%$, low thickness $\mathrm{g}_{\mathrm{m}}=0.4-0.8 \mathrm{~mm}$, and the same small $\left(\mathrm{k}_{\mathrm{m}}=200-250 \mathrm{~g} / \mathrm{m}^{2}\right)$ dust absorptivity limited by the permissible pressure drop $\Delta \mathrm{p}_{\text {fdop }}$ of the air filter [3, 5, 6-9]. Filter papers stop dust grains on the fibers (which have approx. diameter of $20 \mu \mathrm{m}$ ) of the porous barrier due to the various forces, and filtration mechanisms. Over time, dust grains are deeply embedded in the fibrous structure of the filtration media, preventing the proper air flow. As a result, there is a continuous pressure drop on the filter, until the value of $\Delta \mathrm{p}_{\text {fdop }}$ is reached, which is the criterion of air filter usage end, and the exchange of the filter cartridge.

It is believed that all dust grains above $d_{z} \geq 1 \mu \mathrm{m}$ which are of mineral origin cause accelerated components wear of internal combustion engines $[2-5,7,10]$. The air filter responds for supplying air to the engine cylinders of the appropriate quality (purity), to minimize engine components wear.

The development of fiber production technology has caused that more and more often, filter manufacturers, for example: Donaldson, Maan-Hummel, use filtration materials with an additional nanofiber layer. These are the fibers with very small diameters, ranging from 50-1000 nm, which dependins on their production process, and the type of polymer used.

A thin layer of nanofibers applied from the inlet side to a standard filter bed (eg cellulose) retains particles of impurities, before they penetrate into the filter material. The development of fiber production technology has caused that more and more often, filter manufacturers, for example: Donaldson, Maan-Hummel, use filtration materials with an additional nanofiber layer. The dust particles retention on the surface of the layer of nanofibers allows their subse- quent removal (filter cleaning) by means of reverse (in the opposite direction to the direction of air flow during operation) of a compressed air pulse under high pressure. If the dust particles are on the filter material surface, they do not damage (break) the structure of the filter cartridge when they are blown out.

In the available literature, the data characterizing the properties of filtration materials with the addition of nanofibers is not very common. Hence, it is advisable to carry out experimental investigations of filtration materials with the addition of nanofibers in terms of efficiency, filtration performance, and pressure drop. Such studies are expensive and labor-intense, however, this is the most reliable research method.

\section{Air pollution and their impact on engine components wear}

During the operation of combustion engines with air, the significant amounts of contaminants enter into cylinders, but these are mostly dust grains with sizes below 2-5 $\mu \mathrm{m}$ as modern air filters, where filter paper or non-woven fabric is a filter medium, operate with such precision. Larger dust grains enter into the engine cylinders as a result of the failure of the air supply system. The contaminants enter into the engine cylinders also with fuel and oil but their amount is much smaller. The abrasive wear occurs when a hard foreign objects get between two cooperating surfaces, sticking into the different depths, leading to deformation and cutting micro volumes of surface layers of the cooperating components. The literature is dominated by the view that the greatest wear is caused by the dust grains of sizes of $d_{z}$ equal to the minimum $h_{\text {min }}$ thickness of an oil layer needed to create a lubricant film between the cooperating surfaces, that is when there is the following relationship. For any other value of the quotient of $h_{\min } / d_{z}$, connection wear decreases (Fig. 1) [10].

$$
\frac{\mathrm{h}_{\min }}{\mathrm{d}_{z}}=1
$$


The minimum thickness of the oil film $\mathrm{h}_{\min }$ between two abrasively cooperating surfaces is directly proportional to the temperature-dependent oil viscosity $\eta$, the $C$ coefficient depending on the bearing dimensions, relative speed of lubricated surfaces $\mathrm{v}$, and inversely proportional to the $\mathrm{P}$ loading force and is expressed with the general dependency:

$$
\mathrm{h}_{\min }=\eta \cdot \frac{\mathrm{C} \cdot \mathrm{v}}{\mathrm{P}}
$$

a)

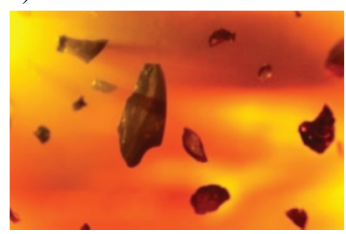

b)

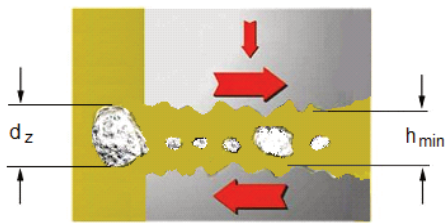

Fig. 1. Effect of solid particulates on a tribological connection: a) contaminations suspended in the oil [1], b) condition of the maximum connection consumption [10]

For the set conditions of the engine operation, the oil film thickness $\mathrm{h}_{\min }$ changes cyclically in a tribological connections area depending on the connection operating conditions. Between a cylinder liner and a piston rings, the oil film thickness is determined by the piston speed (Fig. 2).
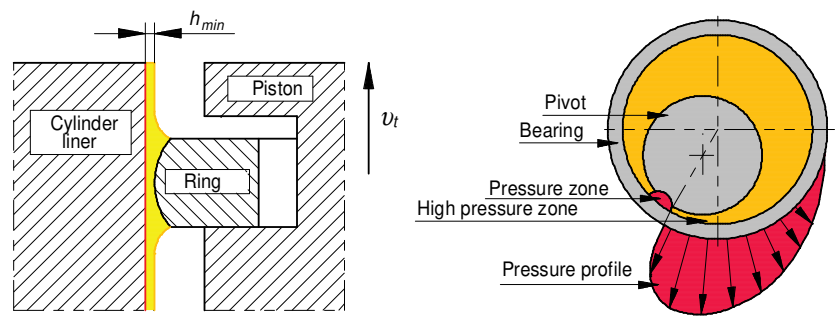

Fig. 2. Formation of an oil film in connections: a) P-R-C, b) pivot - bearing

Between the BDC and UDC dead centres, the piston (piston rings) speed is the largest, thus the thickness of the oil film in this area takes the maximum values. Changing the direction of the piston movement in extreme positions of the cylinder liner makes that its speed in this area is the smallest, and in BDC and UDC is zero, which leads to a reduction of the oil film or its complete disappearance. Therefore, there may be periods of even direct metallic contact between the piston ring and the liner. Under these conditions, in theory, each particle with any small sizes can cause the wear. As a result of the oil film thickness changes, dust grains, which were between the cooperating surfaces, are crushed and grinded and can penetrate between two frictionally cooperating surface, where the oil film thickness takes small values. In typical connections of a combustion engine, the oil film thickness specified in the paper [3] takes different values (Fig. 3).

It is clear that even the smallest dust grains and those below 2-5 $\mu \mathrm{m}$ will result in accelerated wear. It is believed that all the dust grains above $1 \mu \mathrm{m}$ are the cause of accelerated wear, but the dust's abrasive aggressivity decreases when the dust grains sizes are below $5 \mu \mathrm{m}$. However, the dust grains below $1 \mu \mathrm{m}$ are dangerous because they affect the cylinder sliding surface like polishing paste. Oil parti- cles do not adhere to a polished cylinder bearing surface, which leads to breaking the oil film and accelerated wear. The volume consumption of engine components due to the impact of dust depends on: the parameters of the sucked in dust, clearances between cooperating parts, design and operating engine parameters, material mechanical properties. The dust entering with the air into the engine cylinders affects the first piston ring, the piston, and the top cylinder part the most intensively. Applying by-pass filters in engine lubrication systems resulted exactly from the need to remove contaminants of with the dimension of below $1 \mu \mathrm{m}$ from the engine oil.

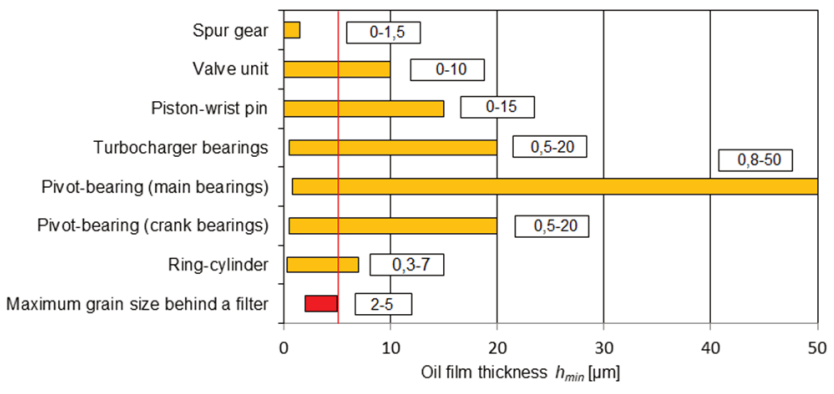

Fig. 3. Oil film thicknesses in typical combustion engine connections [3]

Figure 4 shows the results of the P-R-C connection wear of a 4-cylinder engine with spontaneous ignition $\left(\mathrm{V}_{\mathrm{ss}}=1.3\right.$ $\mathrm{dm}^{3}, \mathrm{~N}_{\mathrm{e}}=66 \mathrm{~kW}$ at $4,000 \mathrm{rpm}, \mathrm{M}_{\mathrm{o}}=200 \mathrm{~N} \cdot \mathrm{m}$ in the range of 1,750-2,250 rpm), turbocharged, with charge air cooling and exhaust gases recirculation after 1,200 hours of operation according to a specified endurance test [18]. The greatest wear of the cylinder liners was registered in their upper part, in the plane perpendicular to (B-B) the engine axis, which is consistent with other studies results [10]. The cylinder liner and piston rings wear caused by contaminants entering into the cylinder liner with the inlet air and contaminants in the oil causes the decline in the rod side area. As a result, there is a loss of the compressed agent, and thus the pressure drop at the end of a compression stroke, and consequently the tested engine power drop by approximately $2.5 \%$ and increase in specific fuel consumption by $3.4 \%$ (Fig. 4).

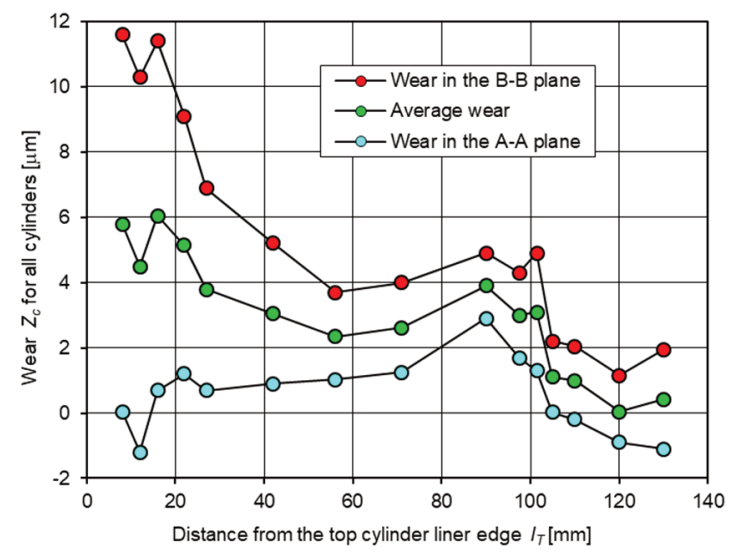

Fig. 4. Cylinder liner wear of a 4-cylinder, turbocharged engine with spontaneous ignition and power $\mathrm{N}_{\mathrm{emax}}=66 \mathrm{~kW}$ in a plane perpendicular (B-B) and parallel (A-A) to the engine axis [18] 
The P-R-C connection wear is also the increase in the intensity of exhaust fumes blow-through into a crank case (Fig. 5), which increases the lubricating oil temperature, decreases its lubricating properties and blowing the oil through exhaust gases. The result of this is a loss of "a lubricant film," and as a result of which the system passes from fluid friction conditions to mitigated solid friction.

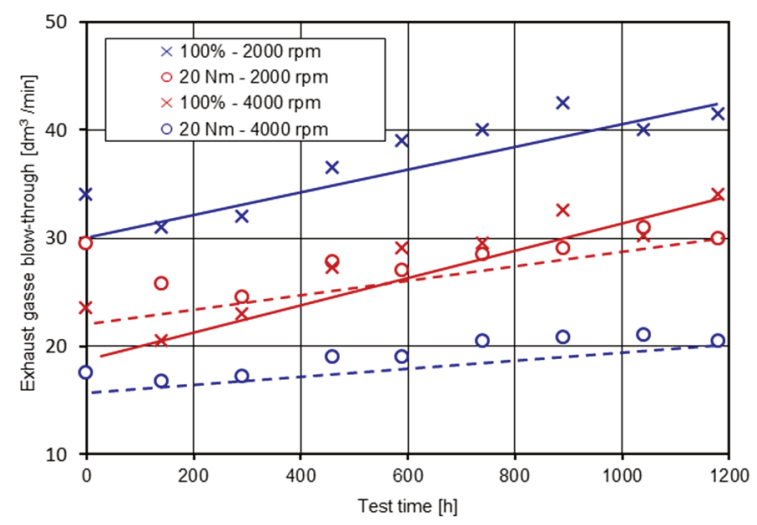

Fig. 5. Effect of the test on: a) the engine exhaust gas blow-through at full and low engine load, b) the engine oil consumption at various engine loads [18]

After 1,200 hours of operation at full load and 4,000 rpm, blow-through intensity increased by $61 \%$. This accelerates considerably the engine oil degradation. The increased looseness in the P-R-C connection intensifies the phenomenon of piston rings operation, thus oil consumption and exhaust fused toxicity increase. At the same time, the engine oil consumption increased by $108 \%, 96 \%$ and $113 \%$ respectively at loads of $100 \%, 33 \%$ and $20 \mathrm{~N} \cdot \mathrm{m}$ (Fig. 6).

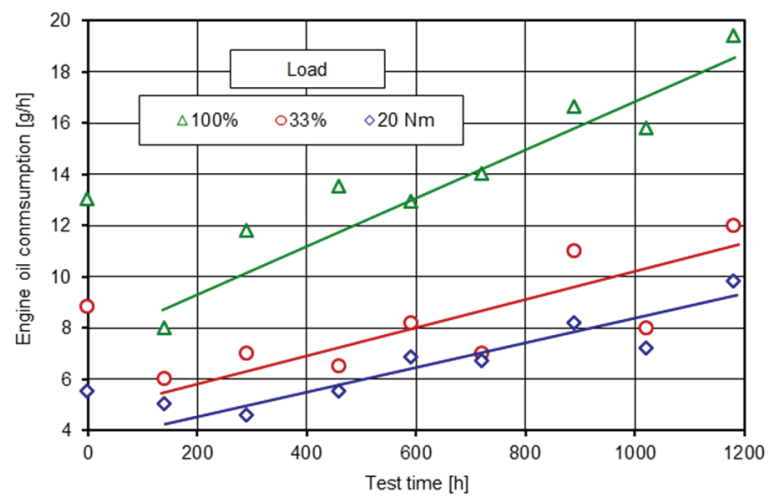

Fig. 6. Effect of the test on: a) the engine exhaust gas blow-through at full and low engine load, b) the engine oil consumption at various engine loads [21]

The accelerated wear of the cylinder liner may be a result of engine operation with an inoperative air filtration system. Figure 7 shows the image of such wear of a truck's cylinder liner.

Abrasive wear of the cylinder bearing surface is visible in the form of parallel, continuous scratches bands along a forming cylinder liner in a cylinder bearing surface top area along approximately $1 / 5$ of the circumference. Scratches were caused by hard and big dust grains. Scratch bands are so intense and deep that traces of final cylinder bearing surface treatment - honing - are invisible (Fig. 7a). Figure $7 \mathrm{~b}$ shows much less wear of the cylinder bearing surface, seen as single scratches over the traces after surface treatment. Figure 7c shows the view of a truck engine's cylinder bearing surface operated with an operative air filtration system. Honing traces and combustion products deposits on the cylinder liner above upper dead centre of the first piston ring are clearly visible.

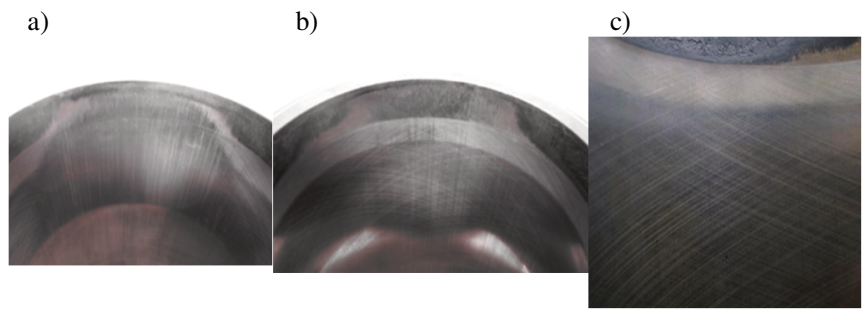

Fig. 7. View of a truck's engine cylinder bearing surface operated with an operative and inoperative air filtration system: a) clear scratches band without honing traces, b) visible single scratches band over surface treatment traces, c) an operative air filtration system [7]

\section{Nanofibers filtration materials properties}

Proper purity of the air supplied to the internal combustion engine piston cylinders is provided by the air filter together with the intake. In today's passenger cars and vans, there are used single-stage filters, which are equipped with filter inserts made of pleated paper (sometimes made of non-woven fabric) shaped in the form of cuboidal panels. For filtering intake air for vehicle engines used in conditions of high dust concentrations in the air, two-stage or three-stage filters are used. The first stage of filtration is then an inertial filter, and the second is a series of a porous barrier made of filter paper behind it. The development of fiber production technology has caused that more and more often filter manufacturers, for example Donaldson, MannHummel, use filtration materials with an additional nanofibers layer to build filtration inserts.

Nanofibers have completely different properties compared to standard fibers. First of all, in relation to the mass, they have a large surface area, much higher strength, and they are also characterized by higher chemical activity, and higher moisture sorption. They can be used to build filters to separate chemical or biological contaminants from the blood plasma, they can be used as gas filters, and impurities with very small diameters - filters with molecular separation. Due to their structure, nanofibers materials have unique properties, and offer unexpected possibilities of their application in many fields, such as in medicine, energy and air filtration [15].

Nanofibers can be made from different polymers, and thus have different physical properties. Examples of natural polymers include collagen, cellulose, silk fibroin, keratin, gelatine and polysaccharides, such as chitosan and alginate. Nanofibers diameter depend on the type of used polymer, and the method of production [19]. All polymer nanofibers are unique due to their large area, and volume, considerable mechanical strength, and small fiber diameter. Filter media made of nanofibers are characterized by high porosity and small pore sizes [11, 13-15].

In automotive industry, fibers with very small diameter of about $0.05-0.8 \mu \mathrm{m}(50-800 \mathrm{~nm})$ are used. As a comparison [25]: 
- cellulose fiber thickness - 10000-20000 nm

- human hair thickness -20 000-80000 nm

- blood red cell diameter - about $7000 \mathrm{~nm}$

- bacteria - $2000 \mathrm{~nm}$.

Figure 8 shows SEM image of nanofibre coated filter medium [23].

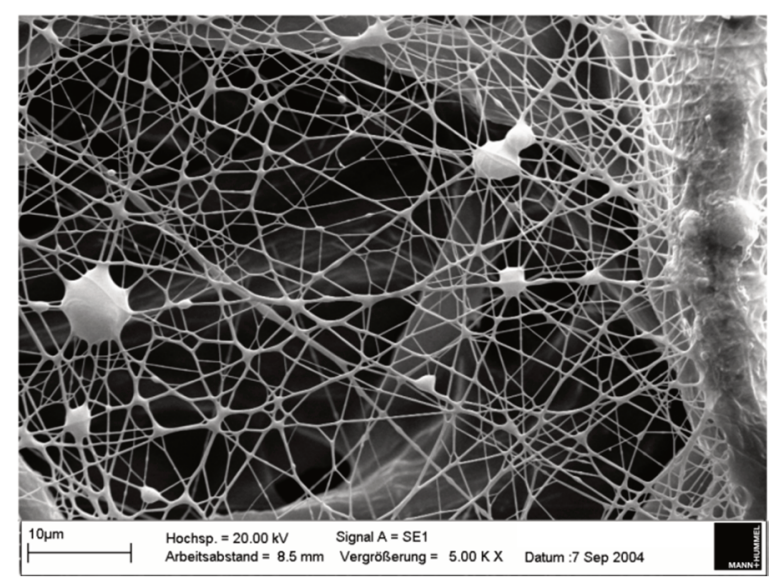

Fig. 8. SEM image of nanofibre coated filter medium [23]

The most widely used method of producing nanofibers is the electrospinning method [19]. It is a process of obtaining fibers from molten polymers or their solutions, using high voltage. This modern technology, using the right polymer, and dissolution system, now allows the production of fibers with diameters ranging from $3 \mathrm{~nm}$ to $1000 \mathrm{~nm}$. Virtually any polymer can be obtained in the form of fibers by electrospinning. Nanofibers have many possible technological, and commercial applications in the following areas: tissue engineering, drug delivery (release), diagnosis of carcinogenic changes, lithium-air batteries, optical sensors, and air filtration.

Due to the limited mechanical, and strength properties of the thin layer of nanofibers $(1-5 \mu \mathrm{m})$, it is applied to the substrate (Fig. 9) from conventional filtration materials that have higher strength. The nanofibers may be laid on one or two sides of the substrate, which may be: cellulose, nylon or polyester. Usage of nanofibers, as an additional layer applied to standard filter materials for air filters used in motor vehicles, significantly increases the efficiency and accuracy of filtration.

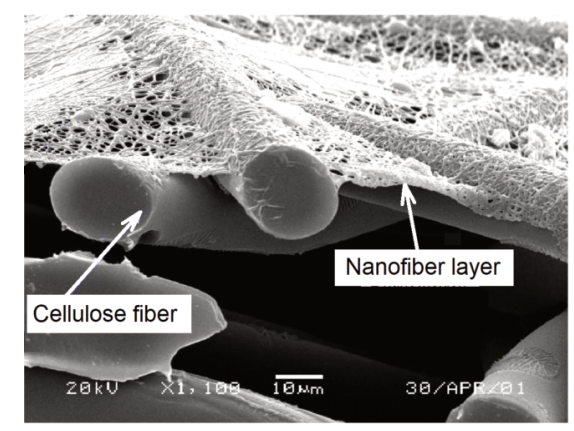

Fig. 9. Nanofibers applied to a cellulose substrate - cross-section view [13]

Figure 10 shows the fractional efficiency of a cellulosebased nanofibre filtration medium, on which a $0.3 \mathrm{~mm}$ nanofiber layer, $\mathrm{g}_{\mathrm{m}}=0.1 \mathrm{~g} / \mathrm{m}^{2}$, and fiber diameter in the range of $40-800 \mathrm{~nm}$ was placed $[15,16]$. With the increase of the dust grain size, the efficiency of filtration for both filter cartridges gets higher and higher values, but the filtration efficiency of the filter cartridge with the nanofibers layer has higher level. For dust grains with $d_{z}=0.25 \mu \mathrm{m}$, filter cartridge filtration efficiency, with the "meltblown" nanofiber layer applied is $\varphi=80 \%$, and for a standard cellulose fiber filter only $\varphi=20 \%$. With the dust grain size, the difference in the filtration efficiency of both cartridges decreases and for $d_{z}=4.5 \mu \mathrm{m}$ it is $99.8 \%$ and $97 \%$ respectively. Nanofibers layer usage on a standard filtration substrate also causes an increase in the pressure drop $\Delta \mathrm{p}$. For the speed $v_{\mathrm{F}}=0.3 \mathrm{~m} / \mathrm{s}$, the insert with the addition of nanofibers has a $75 \%$ higher flow resistance $\Delta p$ than the standard [12]. These values are much higher, than those based on cellulose, and commercial materials with the addition of nanofibers (Fig. 3).

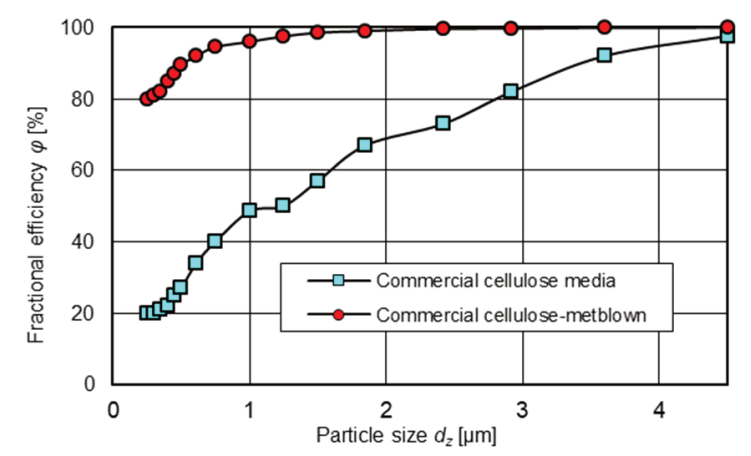

Fig. 10. Pleated filter elements made of cellulose fibers, nanofiber layer and cellulose fibers filtration efficiency [12]

The ratio of the nanofibers to the cellulosic fiber diameter is approximately $1: 130$. This results in a significant increase in the filtration area for the nanofiber bed. Nanofibers area of $1 \mathrm{~g}$, with a diameter of $200 \mathrm{~nm}$ is approximately $20 \mathrm{~m}^{2} / \mathrm{g}$, and only $0.2 \mathrm{~m}^{2} / \mathrm{g}$ for cellulose fibers with a diameter of $20 \mu \mathrm{m}$. Fiber diameter is the main variable responsible for the filtration efficiency, and flow resistance. The efficiency increases rapidly as the fiber diameter decreases. For example, the use of fibers with a diameter of $1 \mu \mathrm{m}$ instead of $50 \mu \mathrm{m}$ leads to an increase in the filtration quality factor by $2000[15,16]$.

Filtration efficiency, filtration performance and pressure drop of filtration materials with an additional nanofiber layer depends on the substrate structure (type of material), and the layer of nanofibers thickness. The paper [14] presents the results of filtration effectiveness tests of four samples made of different filtration materials: 1 - nonwoven, 2 - knitted, 3 - woven, 4 - charmeuse (silk nonwoven).

Filtration efficiency, and pressure drop were determined for samples with nanofiber layers with a basis weight of: $\mathrm{g}_{\mathrm{m}}=0.02 \mathrm{~g} / \mathrm{m}^{2}, \mathrm{~g}_{\mathrm{m}}=0.1 \mathrm{~g} / \mathrm{m}^{2}, \mathrm{~g}_{\mathrm{m}}=0.5 \mathrm{~g} / \mathrm{m}^{2}$, and without a layer of nanofibers. Photos from the SEM microscope for sample $\mathrm{C}$ with a layer of nanofibers with set weights are shown in Fig. 11. The nanofibers had an average diameter of $140 \mathrm{~nm}$ with a standard deviation of $30 \mathrm{~nm}$. The average pore size for the nanofiber layer with the basis weight $\mathrm{g}_{\mathrm{m}}=0.02 \mathrm{~g} / \mathrm{m}^{2}, \mathrm{~g}_{\mathrm{m}}=0.1 \mathrm{~g} / \mathrm{m}^{2}, \mathrm{~g}_{\mathrm{m}}=0.5 \mathrm{~g} / \mathrm{m}^{2}$ were respec- 
tively $1190 \mathrm{~nm}, 540 \mathrm{~nm}$ and $260 \mathrm{~nm}$. The effect of applied nanofiber layer on the filtration efficiency of the filter material (nonwoven fabric 1) is shown in Fig. 12. Material filtration effectiveness without the nanofiber layer is very low, and for particle sizes below $2 \mu \mathrm{m}$ does not exceed $10 \%$. A small layer of nanofibers with $\mathrm{g}_{\mathrm{m}}=0.02 \mathrm{~g} / \mathrm{m}^{2}$ increases the filtration efficiency of particles smaller than $2 \mu \mathrm{m}$ over $60 \%$. Nanofibers layer with $\mathrm{g}_{\mathrm{m}}=0.1 \mathrm{~g} / \mathrm{m}^{2}$ increased the filtration efficiency of particles with dimensions of $2 \mu \mathrm{m}$ to the value of about $90 \%$, and for $\mathrm{g}_{\mathrm{m}}=0.5 \mathrm{~g} / \mathrm{m}^{2}-$ to the value of over $99 \%$. a)

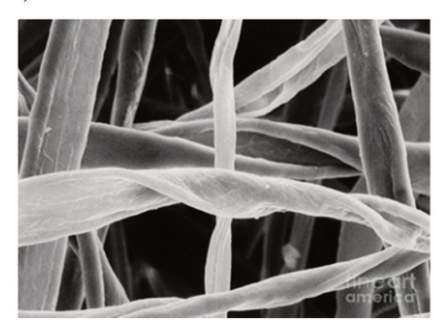

c)

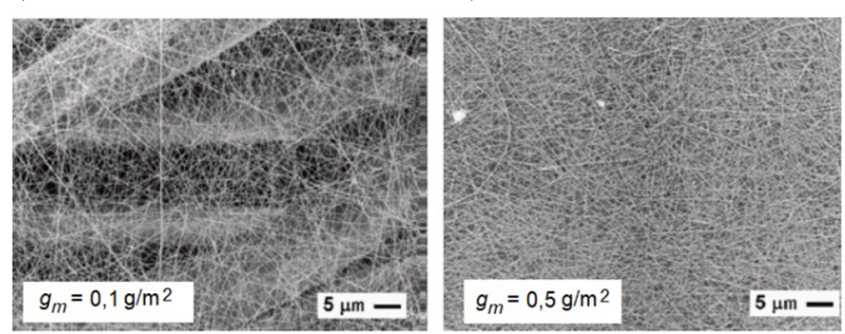

Fig. 11. SEM microscope photographs for sample 3 with nanofiber a basis weight layer: a) without nanofibers, b) $\mathrm{g}_{\mathrm{m}}=0.02 \mathrm{~g} / \mathrm{m}^{2}$, c) $\mathrm{g}_{\mathrm{m}}=0.1 \mathrm{~g} / \mathrm{m}^{2}$, d) $g_{m}=0.5 \mathrm{~g} / \mathrm{m}^{2}[14]$

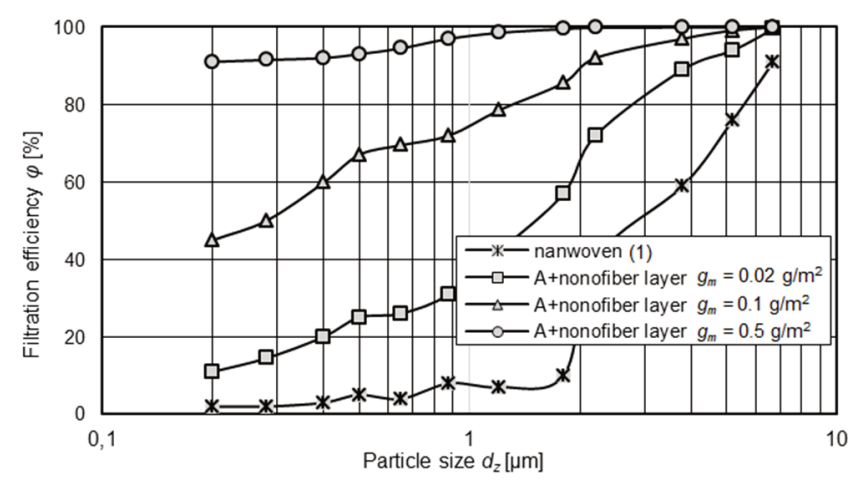

Fig. 12. Material filtration effectiveness (nonwoven fabric sample 1) without a nanofiber layer, and with nanofiber layer with unit weight $\mathrm{g}_{\mathrm{m}}=0.02 \mathrm{~g} / \mathrm{m}^{2}, \mathrm{~g}_{\mathrm{m}}=0.1 \mathrm{~g} / \mathrm{m}^{2}, \mathrm{~g}_{\mathrm{m}}=0.5 \mathrm{~g} / \mathrm{m}^{2}[14]$

There are known constructional solutions for vehicle inlet air filters (Abrams M1 tank), where a filter cartridge with the addition of nanofibers, and a system of automatic impulse purification of the PJCA (Pulse Jet Air Cleaner) filter cartridge is used [12]. It ensures several times longer air filter life, and thus longer vehicle life without the need to operate the filter. The principle of PJAC operation system is that at the time when the pressure drop of the filter inflow does not exceed the permissible value, the air filtration process takes place, as in every vehicle filter. After pressure drop reaches certain value, a pressure modulator is activated for $0.1-0.35 \mathrm{~s}$, producing a pulse in the form of compressed air with a pressure of 0.4-0.6 MPa. Compressed air flowing in the opposite direction, to the air flow direction during the filtration process blows out dust particles from the surface of the filter cartridge, which then fall into the dust collector [20].

Figure 13 shows that the standard filter cartridge, mounted in a tank which moves in the column in desert conditions, reaches the permissible value of pressure drop, $\Delta \mathrm{p}_{\text {fdop }}=7.6 \mathrm{kPa}\left(30\right.$ inches of $\mathrm{H}_{2} \mathrm{O}$ ) after driving about 25 $\mathrm{km}$ (16 miles).

When a filter cartridge with a nanofiber layer equipped with an automatic pulse cleaning system reaches maximum pressure drop of approximately $6.3 \mathrm{kPa}\left(25\right.$ inches of $\mathrm{H}_{2} \mathrm{O}$ ), the pulse cleaning system will be activated. After removing the dust from the nanofiber layer, the pressure drop decreases to approximately $5 \mathrm{kPa}\left(20\right.$ inches of $\left.\mathrm{H}_{2} \mathrm{O}\right)$, and remains at this level.

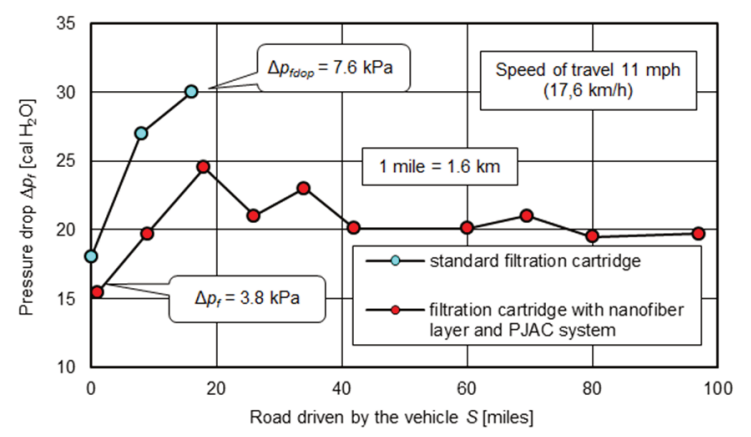

Fig. 13. Air cleaner pressure drop versus miles traveled in $20 \mathrm{mph}$ convoy test in desert conditions and automatic cleaning system [12]

\section{Author's own research}

\subsection{Aim, scope and research subject}

The aim of the research was to determine, and compare filtration properties: efficiency and accuracy of filtration, and filter cartridges flow resistance made of various filter materials (cellulose, polyester with the addition of nanofibers) by determining their following characteristics:

- filtration performance $\mathrm{d}_{\mathrm{zmax}}=\mathrm{f}\left(\mathrm{k}_{\mathrm{m}}\right)$,

- filtration efficiency $\varphi_{\mathrm{w}}=\mathrm{f}\left(\mathrm{k}_{\mathrm{m}}\right)$,

- $\quad$ pressure drop $\Delta \mathrm{p}_{\mathrm{w}}=\mathrm{f}\left(\mathrm{k}_{\mathrm{m}}\right)$,

where: $\mathrm{k}_{\mathrm{m}}$ - dust mass loading, determining dust mass $\mathrm{m}_{\mathrm{w}}$ retained, and evenly distributed over $1 \mathrm{~m}^{2}$ of filter material active surface, which is expressed by the dependence:

$$
\mathrm{k}_{\mathrm{m}}=\frac{\mathrm{m}_{\mathrm{w}}}{\mathrm{A}_{\mathrm{w}}}\left[\mathrm{g} / \mathrm{m}^{2}\right]
$$

The filtration speed is defined as the quotient of the air stream flowing through the filter cartridge $Q_{w}$ (equal to the engine air demand), and the area of the active paper filter $A_{w}$, and is expressed by the following relationship:

$$
\mathrm{v}_{\mathrm{FW}}=\frac{\mathrm{Q}_{\mathrm{w}}}{\mathrm{A}_{\mathrm{w}} \times 3600}[\mathrm{~m} / \mathrm{s}] \text {. }
$$

The subject of the research were four filter cartridges of the same type, same dimensions, same filtration surface $\mathrm{A}_{\mathrm{w}}=0.153 \mathrm{~m}^{2}$, but differing in the filter material (Fig. 14). 
On two standard filtration materials, there is a nanofiber layer on the inlet side. In order make test analysis easier, filter materials have been labelled as follows:

- A (cellulose),

- B (polyester),

- C (cellulose + polyester + nanofiber layer),

- D (polyester + nanofiber layer).

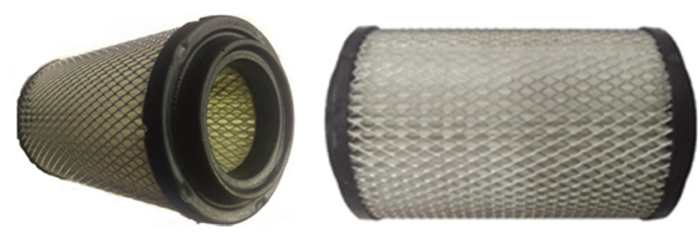

Fig. 14. Filter cartridge

Tested filter materials characteristic parameters are summarized in Table 1. Three times higher air permeability, and double the size of the filter material A (cellulose) pores from other materials is noteworthy.

Table 1. Tested filtration materials parameters according to the manufacturer's data

\begin{tabular}{|c|c|c|c|c|}
\hline $\begin{array}{c}\text { Filter paper } \\
\text { identification }\end{array}$ & Filtration material & $\begin{array}{c}\text { Permeability } \\
\mathrm{q}_{\mathrm{p}}\left[\mathrm{m}^{3} / \mathrm{m}^{2} / \mathrm{h}\right], \\
200[\mathrm{~Pa}]\end{array}$ & $\begin{array}{c}\text { Grammage } \\
\mathrm{g}_{\mathrm{m}}\left[\mathrm{g} / \mathrm{m}^{2}\right]\end{array}$ & $\begin{array}{c}\text { Thickness } \\
\mathrm{g}_{\mathrm{z}}[\mu \mathrm{m}]\end{array}$ \\
\hline A & Cellulose & 3017 & 121 & 610 \\
\hline B & Polyester & 650 & 180 & 500 \\
\hline C & $\begin{array}{c}\text { Cellulose + polyester } \\
+ \text { nanofibers }\end{array}$ & 660 & 120 & 300 \\
\hline D & $\begin{array}{c}\text { Polyester } \\
+ \text { nanofibers }\end{array}$ & 525 & 180 & 500 \\
\hline
\end{tabular}

\subsection{Methodology and test conditions}

Tests were carried out at the station (Fig. 15), which was equipped with the Pamas-2132 particle counter with the HCB-LD-2A-2000-1 sensor. The meter registers the number and size of dust grains in the air stream Q, behind the tested filter cartridge in the range of $0.7-100 \mu \mathrm{m}$ in $\mathrm{i}=32$ measurement intervals, limited by diameters $\left(\mathrm{d}_{\text {zimin }}-\mathrm{d}_{\text {zimax }}\right)$.

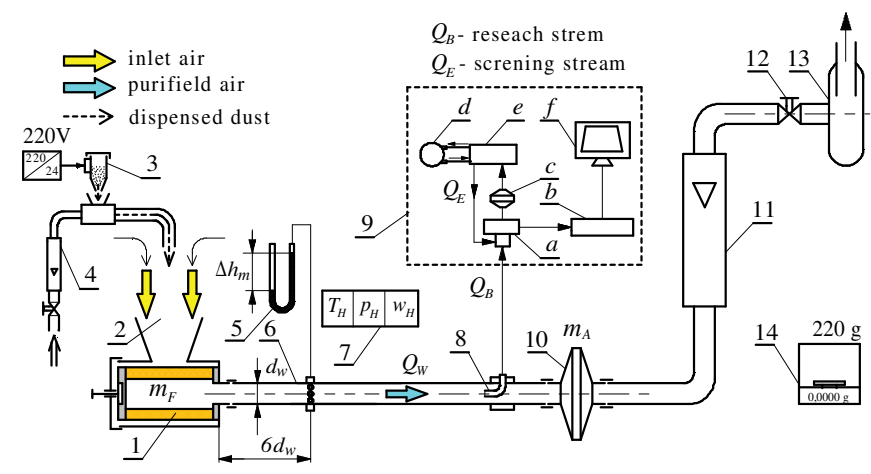

Fig. 15. Filter cartridge test stand functional diagram: 1 - filter cartridge, 2 - dust chamber, 3 - dust dispenser, 4 - rotameter, 5 - U-type manometer tube, 6 - measuring tube, 7 - humidity measurement set , ambient air temperature and pressure, 8 - measuring probe, 9 - particle counter ( $\mathrm{a}$ - sensor, b - counter microprocessor, $\mathrm{c}$ - test stream filter, $\mathrm{d}$ - vacuum pump, e - flow control block, f - measuring computer), 10 - absolute filter, 11 - rotameter, 12 - air stream regulation valve, 13 - suction fan, 14 - analytical balance
During the tests, a research cycle was applied, in which five counts of the dust grains in the range $0.7-20 \mu \mathrm{m}$ were programmed, divided into 20 identical measurement intervals limited with diameters $\left(\mathrm{d}_{\mathrm{zimin}}-\mathrm{d}_{\text {zimax }}\right)$ with a step of $\Delta \mathrm{d}_{\mathrm{zi}}=0.4 \mu \mathrm{m}(0.7-1.1 \mu \mathrm{m} ; 1.1-1.5 \mu \mathrm{m} ; 1.5-1.9 \mu \mathrm{m} ; \ldots$; 8.3-8.7 $\mu \mathrm{m})$ and 11 identical measurement intervals limited with diameters $\left(\mathrm{d}_{\mathrm{zimin}}-\mathrm{d}_{\mathrm{zimax}}\right)$ with a step of $\Delta \mathrm{d}_{\mathrm{zi}}=0.8 \mu \mathrm{m}$ (8.7-9.5 $\mu \mathrm{m} ; 9.5-10.3 \mu \mathrm{m} ; 10.3-11.1 \mu \mathrm{m} ; \ldots$; 15.9-16.7 $\mu \mathrm{m})$. The last measuring compartment had a range of $\Delta \mathrm{d}_{\mathrm{zi}}=$ 16.7-20 $\mu \mathrm{m}$.

At the appropriate distance after tested filter, the tip of the measuring probe is placed centrally in the axis of the cable, which is followed by air suction to the particle counter sensor. The measuring lead ends with a special (absolute) filter, which prevents dust from entering the rotameter, and at the same time it is a measuring filter. The cover in which the cylindrical filter cartridge is located, PTC-D (Fig. 16) test dust is being dispensed as the national replacement for AC fine test dust, whose chemical, and fractional composition is given in [21].

The pressure drop $\Delta \mathrm{p}_{\mathrm{w}}$ in the cartridge was defined as the decrease of the static pressure in the outlet pipe at a distance of $6 d_{w}$ from the edge of the cartridge outlet on the basis of the $\Delta \mathrm{h}_{\mathrm{mj}}\left[\mathrm{mm} \mathrm{H} \mathrm{H}_{2} \mathrm{O}\right]$ indicator on the U-tube liquid manometer, according to the relationship:

$$
\Delta \mathrm{p}_{\mathrm{wj}}=\frac{\Delta \mathrm{h}_{\mathrm{mj}}}{1000} \cdot\left(\rho_{\mathrm{m}}-\rho_{\mathrm{H}}\right) \cdot \mathrm{g}[\mathrm{kPa}]
$$

where: $\rho_{\mathrm{m}}-$ manometric liquid density $\left[\mathrm{kg} / \mathrm{m}^{-3}\right], \rho_{\mathrm{H}}-$ air density $\left[\mathrm{kg} / \mathrm{m}^{-3}\right], \mathrm{g}-$ gravity acceleration $\left[\mathrm{m} / \mathrm{s}^{2}\right]$.
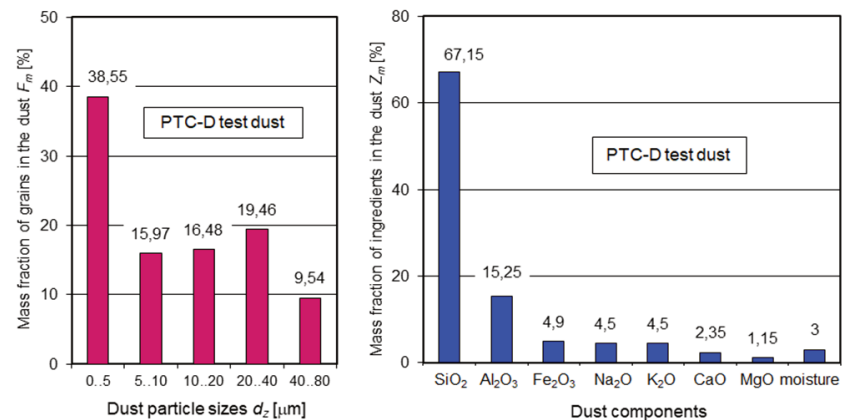

Fig. 16. PTC-D test dust used for testing: a) size distribution, b) chemical composition (PN - ISO 5011)

Cartridges filtration characteristics were determined for the filtration speed $v_{\mathrm{Fw}}=0.1 \mathrm{~m} / \mathrm{s}$. For passenger car filters, the maximum speed of paper filtration is in the range of $0.07-0.12 \mathrm{~m} / \mathrm{s}[3,4,8,9,22]$. For the assumed filtration rate $\left(v_{\mathrm{FW}}=0,1 \mathrm{~m} / \mathrm{s}\right)$, the maximum value of the test stream calculated according to the following relationship has the value $\mathrm{Q}_{\mathrm{wmax}}=56 \mathrm{~m}^{3} / \mathrm{h}$.

$$
\mathrm{Q}_{\mathrm{wmax}}=\mathrm{A}_{\mathrm{w}} \cdot \mathrm{v}_{\mathrm{Fw}} \cdot 3600\left[\mathrm{~m}^{3} / \mathrm{h}\right]
$$

where: tested inserts filtration surface $A_{w}=0.153 \mathrm{~m}^{2}$.

The RIN 60 rotameter of the measuring range 3-67 $\mathrm{m}^{3} / \mathrm{h}$ and the accuracy class 2.5 was assumed for air stream measurement.

Tested filtration materials filtration characteristics were determined by the gravimetric method. Dust mass retained 
on the tested filter cartridge, and the absolute filter was determined in subsequent measuring cycles with a specified duration. The concentration of dust in the inlet air to the filter cartridge $\mathrm{s}=0.5 \mathrm{~g} / \mathrm{m}^{3}$ was used. The tests were carried out in measuring cycles $\mathrm{j}$ with duration (time of equal dust dosing) $\tau_{\mathrm{p}}=3 \mathrm{~min}$. in the initial period, and $\tau_{\mathrm{p}}=9-12 \mathrm{~min}$ in the basic period of filter cartridges work. After each measuring cycle $\mathrm{j}$, the parameters necessary to calculate: efficiency, filtration performance, pressure drop and dust mass loading of the filter cartridge were determined. The dust mass was determined by an analytical balance with a measuring range of $220 \mathrm{~g}$ and an accuracy of $0.1 \mathrm{mg}$.

The tests were performed in measurement cycles resulting from time $t_{p}$ of even dust dispense to the filter. During the measurement cycle at a moment $t_{z}=1 / 2 t_{p}$, the procedure of counting of the particle number and measurement of its size was initiated in the counter downstream of the filter.

After each $\mathrm{j}$-th measurement cycle the following were determined:

- The pressure drop $\Delta \mathrm{p}_{\mathrm{w}}$ in the cartridge was defined as the decrease of the static pressure in the outlet pipe at a distance of $6 d_{w}$ from the edge of the cartridge outlet on the basis of the $\Delta \mathrm{h}_{\mathrm{mj}}\left[\mathrm{mm} \mathrm{H}_{2} \mathrm{O}\right]$ indicator on the U-tube liquid manometer, according to the relationship:

$$
\Delta \mathrm{p}_{\mathrm{wj}}=\frac{\Delta \mathrm{h}_{\mathrm{mj}}}{1000} \cdot\left(\rho_{\mathrm{m}}-\rho_{\mathrm{H}}\right) \cdot \mathrm{g}[\mathrm{kPa}]
$$

where: $\rho_{\mathrm{m}}-$ manometric liquid density $\left[\mathrm{kg} / \mathrm{m}^{3}\right], \rho_{\mathrm{H}}-$ air density $\left[\mathrm{kg} / \mathrm{m}^{3}\right], \mathrm{g}-$ gravity acceleration $\left[\mathrm{m} / \mathrm{s}^{2}\right]$.

- The efficiency of filtration, as a quotient of the mass of the dust $m_{\mathrm{FFj}}$ trapped by the filter and the mass of the dust $\mathrm{m}_{\mathrm{Dj}}$ introduced into the filter during the subsequent $\mathrm{j}$-th measurement cycle based on the relation:

$$
\varphi_{j}=\frac{m_{F j}}{m_{D j}}=\frac{m_{F j}}{m_{F j}+m_{A j}} 100 \%,
$$

- Mass loading of dust $\mathrm{k}_{\mathrm{mj}}$ of the investigated filtration material:

$$
\mathrm{k}_{\mathrm{mj}}=\frac{\sum_{\mathrm{j}=1}^{\mathrm{n}} \mathrm{m}_{\mathrm{Fj}}}{\mathrm{A}_{\mathrm{w}}}\left[\mathrm{g} / \mathrm{m}^{2}\right] .
$$

- The number $\mathrm{N}_{\mathrm{zi}}$ of the dust grains in the airflow downstream of the filter (passed through by the filtering material) in the measurement intervals limited with diameters $\left(\mathrm{d}_{\text {zimin }} \div \mathrm{d}_{\text {zimax }}\right)$.

- The accuracy of filtration - as the greatest size of the dust grain $d_{z j}=d_{z \max }$ in the airflow downstream of the filter.

- Percentage share of individual dust grain fractions in the air downstream of the filter for a given test cycle:

$$
\mathrm{U}_{\mathrm{zi}}=\frac{\mathrm{N}_{\mathrm{zi}}}{\mathrm{N}_{\mathrm{z}}}=\frac{\mathrm{N}_{\mathrm{zi}}}{\sum_{\mathrm{i}=1}^{32} \mathrm{~N}_{\mathrm{zi}}} 100 \%,
$$

where: $\mathrm{N}_{\mathrm{z}}=\sum_{\mathrm{i}=1}^{32} \mathrm{~N}_{\mathrm{zi}}$ - total number of dust grains passed through by the filter (from all measurement intervals) in the test cycle.

\subsection{Test results analysis}

Test results filtration efficiency $\varphi_{\mathrm{f}}$, filtration performance $\mathrm{d}_{\mathrm{zmax}}$, and pressure drop $\Delta \mathrm{p}_{\mathrm{f}}$ calculations of tested filtration materials are shown in Fig. 17. As the dust mass retained in the filtration layer increases $\left(\mathrm{k}_{\mathrm{m}}\right.$ coefficient increase) the filtration efficiency, filtration performance and pressure drop of filter cartridges assume increasing values. This is the result of the space filling between the fibers (pores), which is consistent with the literature $[4,5,8,15,16]$.

The work of tested filter cartridges can be divided into two stages. It was assumed that the first (I), the initial stage of filter cartridges operation, lasts until the filtration efficiency stabilizes at the level of $\varphi_{\mathrm{w}}=99.9 \%$. This stage is characterized by low initial efficiency, filtration performance, and low pressure drop.

For a filter cartridge made of filter material A (cellulose), the initial filtration efficiency is $\varphi_{\mathrm{wA}}=96.5 \%$, and the maximum grain size does not exceed the value of $\mathrm{d}_{\text {zmaxA }}=16.7 \mu \mathrm{m}$. The determined value of filtration efficiency $\left(\varphi_{\mathrm{w}}=99.9 \%\right)$ is achieved at the dust mass loading $\mathrm{k}_{\mathrm{mA}}=91 \mathrm{~g} / \mathrm{m}^{2}$, while the pressure drop increase is insignificant. For the other cartridges made of other filtration materials, the first stage is much shorter.

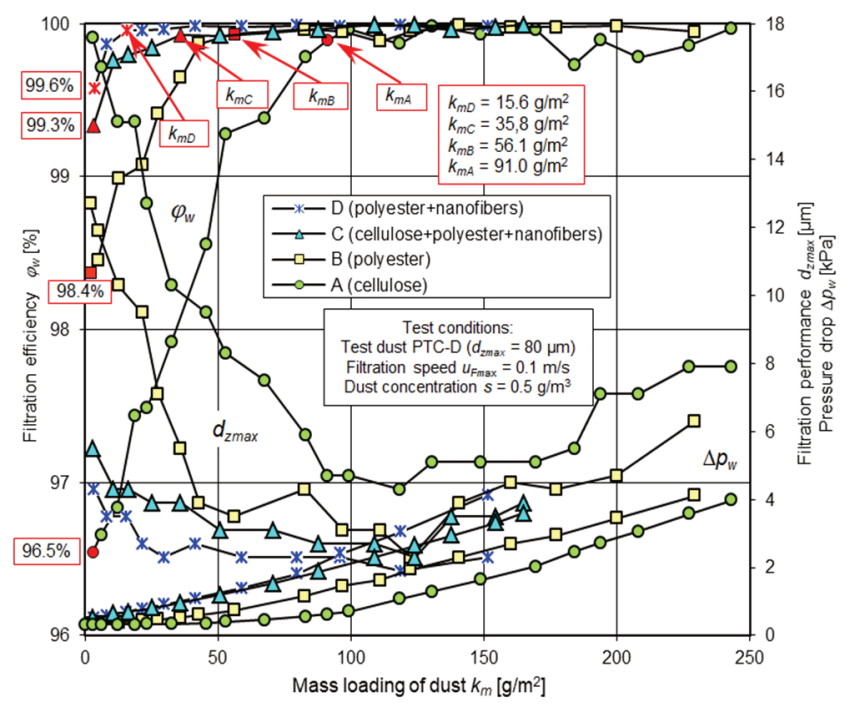

Fig. 17. Filtration efficiency $\varphi_{\mathrm{w}}$, filtration performance, $d_{\mathrm{zmax}}$, and pressure drop $\Delta \mathrm{p}_{\mathrm{w}}$ depending on the tested filter cartridges dust mass loading $\mathrm{k}_{\mathrm{m}}$

For the B (polyester) insert, stage (I) ends with the dust mass loading $\mathrm{k}_{\mathrm{mB}}=56.1 \mathrm{~g} / \mathrm{m}^{2}$, for the cartridge $\mathrm{C}$ (cellulose + polyester + nanofibers) $\mathrm{k}_{\mathrm{mC}}=35.8 \mathrm{~g} / \mathrm{m}^{2}$, and for the contribution $\mathrm{D}$ (polyester + nanofibers) coefficient $\mathrm{k}_{\mathrm{mD}}=15.6$ $\mathrm{g} / \mathrm{m}^{2}$. The initial filtration efficiency for the mentioned cartridges is assumed to be higher, respectively: $\varphi_{\mathrm{wB}}=98.4 \%, \varphi_{\mathrm{wC}}=99.3 \%, \varphi_{\mathrm{wD}}=99.6 \%$. At the end of the first stage filtration, the sizes of the maximum grains for the contributions $\mathrm{A}, \mathrm{B}, \mathrm{C}, \mathrm{D}$ are stabilized at the following level: $\mathrm{d}_{\mathrm{zmaxA}}=4.7 \mu \mathrm{m}, \quad \mathrm{d}_{\mathrm{zmaxB}}=3.9 \mu \mathrm{m}, \quad \mathrm{d}_{\mathrm{zmaxC}}=3.1 \mu \mathrm{m}$, $\mathrm{d}_{\mathrm{zmaxD}}=3.5 \mu \mathrm{m}$.

The initial work stage of the A cartridge made of cellulose is several times longer than the insert $\mathrm{D}$ (polyester with a layer of nanofibers) and the contribution of $\mathrm{C}$ (cellulose + polyester + nanofibers). At the same time, the required high filtration efficiency of the inserts with nanofiber layer reach much earlier than cartridges made of standard filter material. This confirms the literature information about the positive nanofibers influence on the filtration efficiency, and filtration performance materials used in automotive industry. 
In the first filtration stage, the dirt particles deposit on the fibers surface of the porous structure, and on previously deposited particles. In this way, they form slowly growing complicated dendritic structures (agglomerates) that fill free spaces between fibers. They affect the flow field around the fibers. In response to changes in the filter structure, there are changes in the air flow. This has the effect of increasing the flow resistance through the filter bed.

In the second (II) stage of the filtration cartridges, the filtration efficiency remains unchanged, stabilized $\varphi_{\mathrm{w}}=99.9 \%$. In contrast, the pressure drop reaches higher, and higher values, but the intensity of growth is greater for inserts made of materials with nanofibers addition. Filter cartridge $\mathrm{D}$ achieves pressure drop $\Delta \mathrm{p}_{\operatorname{maxD}}=4.1 \mathrm{kPa}$ with dust mass loading of $\mathrm{k}_{\mathrm{mD}}=151.6 \mathrm{~g} / \mathrm{m}^{2}$. Filter cartridge $\mathrm{A}$ similar pressure drop value $\left(\Delta \mathrm{p}_{\operatorname{maxA}}=3.96 \mathrm{kPa}\right)$ achieves at the dust mass loading $\mathrm{k}_{\mathrm{mA}}=243 \mathrm{~g} / \mathrm{m}^{2}$. Inserts with nanofiber layer are characterized by lower dust absorption. This is determined by the surface filtration, as a result of which the dust grains are not allowed into the deposit, but are mostly retained on the nanofiber layer. This is illustrated by the measurement results (Fig. 17) of the maximum dust grains size $d_{z m a x}$ in the air after the tested cartridges. In the air after the insert $\mathrm{A}$ (cellulose) there are grains with the dimensions of $\mathrm{d}_{\text {zmaxA }}=4.3-16.7 \mu \mathrm{m}$, and behind the insert $\mathrm{D}$, where there is nanofiber layer, grains with much smaller dimensions $\mathrm{d}_{\mathrm{zmaxD}}=2.3-4.3 \mu \mathrm{m}$.

Filter elements made of cellulose composite and polyester, together with the applied layer of nanofibers, are characterized by higher efficiency, and filtration performance in the whole range of work (smaller dust grain sizes $d_{z \max }$ in the air behind the filter cartridge) than inserts made of filter material without a layer of nanofibers.

With the increase of dust mass retained in the filtration layer $\left(\mathrm{k}_{\mathrm{m}}\right.$ coefficient increase), filter cartridge flow resistance has higher and higher values. The increase in flow resistance is greater for cartridges $(C, D)$ that have an additional nanofiber layer. Therefore, the cartridges will achieve determined permissible resistance value faster during usage of the car $\Delta \mathrm{p}_{\mathrm{wdop}}=4 \mathrm{kPa}$ (Fig. 18).

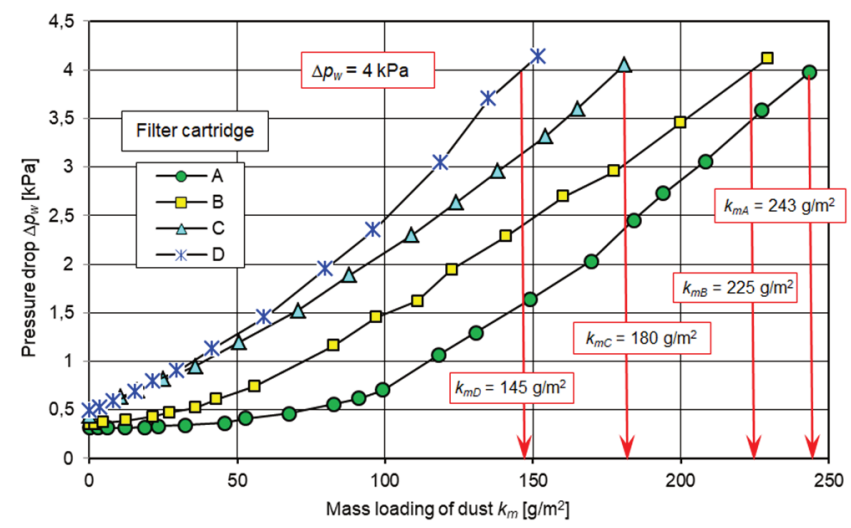

Fig. 18. Filter cartridges pressure drop depending on mass loading coefficient $\mathrm{k}_{\mathrm{m}}$

Filter inserts with a nanofiber layer obtain a maximum mass loading of dust of $\mathrm{k}_{\mathrm{m}}=145-180 \mathrm{~g} / \mathrm{m}^{2}$ (Fig. 18). For a similar pressure drop value $\Delta \mathrm{p}_{\mathrm{wdop}}$ (about $4 \mathrm{kPa}$ ) filter cartridges without nanofibers layer obtain dust mass loading in the range of $\mathrm{k}_{\mathrm{m}}=225-243 \mathrm{~g} / \mathrm{m}^{2}$, which is $50 \%$ more value. This is due to the lower pressure drop intensity of the filter cartridges without the nanofibers layer. After the filtration inserts with nanofiber layer have a pressure drop of $4 \mathrm{kPa}$, the phenomenon of dust agglomeration from the filter bed is observed. This is a proof that in filter beds with nanofiber layer, mainly surface filtration occurs, not deep.

Reaching allowed resistance by the filter (for tested ones $\Delta \mathrm{p}_{\mathrm{wdop}}=4 \mathrm{kPa}$ ) forces user to change the filter cartridge. When using filter cartridges with nanofiber layer their exchange intervals will be shorter.

Low efficiency, and filtration performance in the initial period of filter cartridges work without nanofibers layer (this is the case after replacing a contaminated filter cartridge with a new one) causes that dust particles larger than $1 \mu \mathrm{m}$ in the air entering the engine can have a significant impact on accelerated wear of engine components, mainly cylinder funnel - piston ring-cylinder, association. Such phenomenon is not observed, when using filter cartridges with a layer of nanofibers.

In the final stage of filtration, large dust grains $\left(d_{\text {zmaxA }}=7.9 \mu \mathrm{m}\right)$ are found in the air behind the filter cartridge A. There is also a noticeable decrease in cartridge filtration (Fig. 17). This indicates that the grains have passed to the outlet side of the filter material. In the final stage, a significant dust mass is accumulated in the form of expanded tree-like dendrites. The dust grains located at the very top of the dendrites are entrained and transferred to the outlet side of the filter material. As a result of this phenomenon, along with the inlet air, dust flows into the engine cylinders. Measurements results of dust grains numbers in the air after the tested filter cartridge (passed through the filter material) are shown in Figs 19 and 21, and after over a dozen measurements in the drawing 20 and 22.

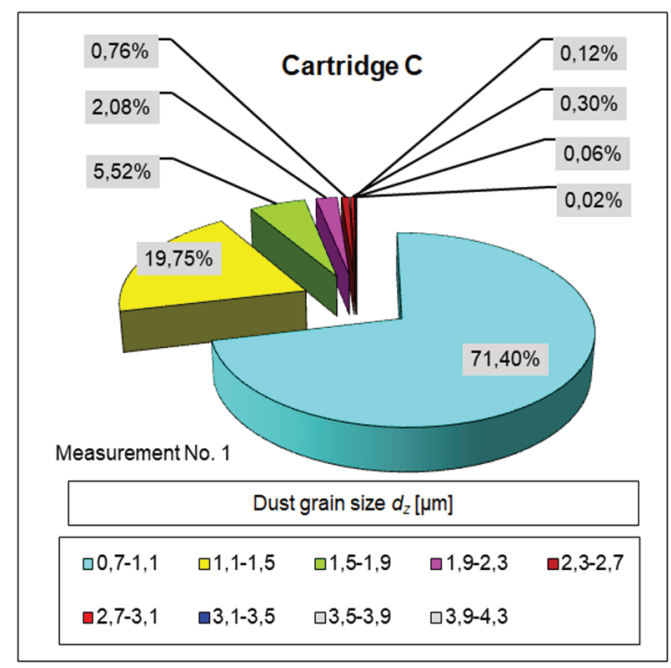

Fig. 19. Granular composition of dust grains assumed by the filter cartridge $\mathrm{C}$ (cellulose + polyester + nanofibers) after reaching dust mass loading $\mathrm{k}_{\mathrm{m}}=3 \mathrm{~g} / \mathrm{m}^{2}$

The largest part in the air are dust grain which have dimensions of $0.7-1.1 \mu \mathrm{m}$. For filter cartridge $\mathrm{C}$, this is a constant value, slightly over $70 \%$. For the first measurement, the part of dust grains in the range of $0.7-1.1 \mu \mathrm{m}$ is 
$\mathrm{U}_{\mathrm{z} 1}=71 \%$, for the measurement number $3-\mathrm{U}_{\mathrm{z} 3}=73 \%$, and for the measurement number $8-\mathrm{U}_{\mathrm{z} 8}=72 \%$. For the remaining measuring compartments, the part of dust grains in the air with each measurement decreases, which indicates the increasing filtration efficiency of the tested material. After the filter achieved the maximum efficiency of $\varphi_{\max }=99.99 \%$, there were dust particles smaller than $2.7 \mu \mathrm{m}$ in purified air.

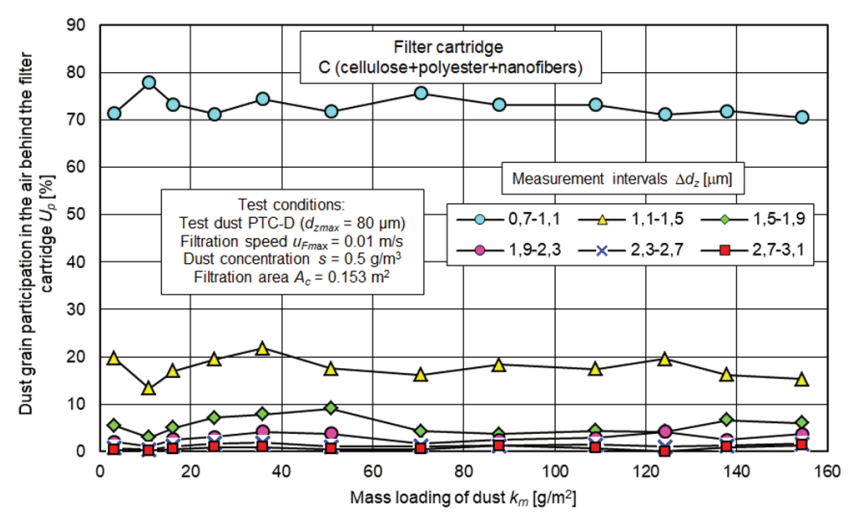

Fig. 20. Dust grains granulometric composition which passed through filter cartridge $\mathrm{C}$ (cellulose + polyester + nanofibers)

Part of dust grains of $0.7-1.1 \mu \mathrm{m}$ for the filter cartridge A (cellulose) is much smaller than the contribution of $\mathrm{C}(27 \%$ at the time of the first measurement) and increases to $85 \%$, and then decreases to about $70 \%$ (Fig. 21 and Fig. 22).

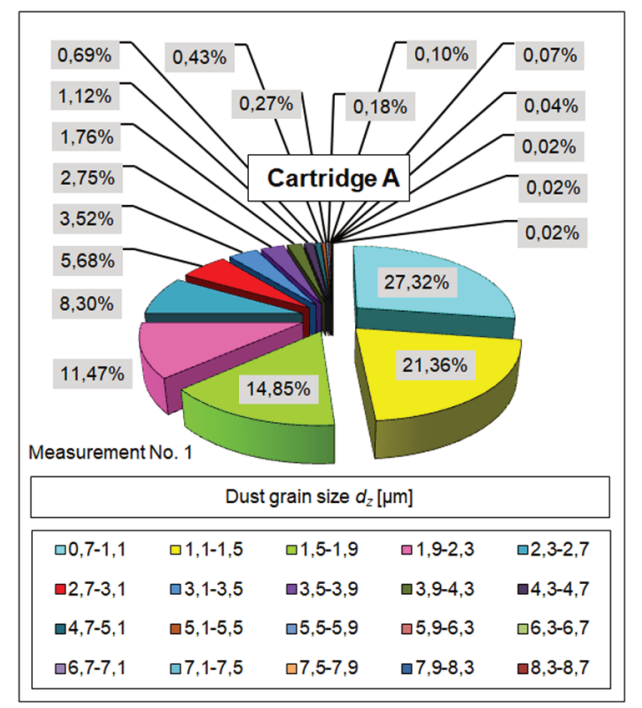

Fig. 21. Granular composition of dust grains assumed by the filter cartridge A (cellulose) after reaching the dust mass loading $\mathrm{k}_{\mathrm{m}}=2.8 \mathrm{~g} / \mathrm{m}^{2}$

The share of dust grains of $1.1-1.5 \mu \mathrm{m}$ size is in the range of $20-27 \%$ until reaching the dust mass loading $\mathrm{k}_{\mathrm{m}}=67 \mathrm{~g} / \mathrm{m}^{2}$, and then decreases to about $18 \%$, after which it remains at a constant level. For the next measurement intervals, including dust grains above $1.5 \mu \mathrm{m}$, the shares of dust grains are getting smaller (Fig. 20), and their changes depending on the $\mathrm{k}_{\mathrm{m}}$ coefficient are similar to the shares of dust grains in the 1.1 to $1.5 \mu \mathrm{m}$ range. In the air behind the filter cartridge A (made of cellulose) after reaching the maximum filtration efficiency $\varphi_{\max }=99.96 \%$ there were dust grains with dimensions below $4.7 \mu \mathrm{m}$.

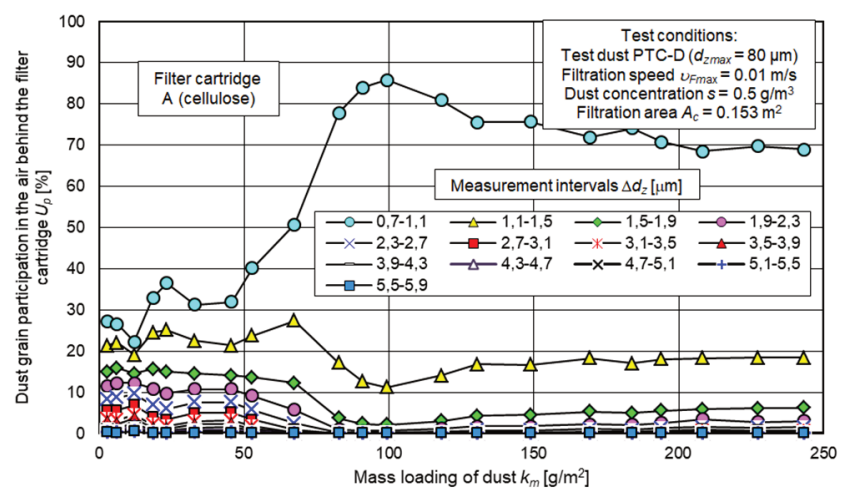

Fig. 22. Dust grains granulometric composition which passed through filter cartridge A (cellulose)

\section{Conclusions}

1) Nanofiber layer with a thickness of few micrometers applied on a substrate made of conventional filter materials for car air filters increase the filtration efficiency and filtration performance, especially for dust grains below $5 \mu \mathrm{m}$, without a significant pressure drop. As a result, the abrasive wear of engine components, especially those (piston-piston rings-cylinder combination), which decide about the correct combustion process and the power obtained, is reduced.

2) The available literature data has a limited amount of information when it comes to filtration filter inserts properties with nanofiber layer, and all the values of filtration efficiency, and accuracy, hence it is advisable to carry out experimental research.

3) Filtration materials with nanofiber addition create, upon reaching a certain value of the flow resistance, the possibility of impulse cleaning them, with a stream of compressed air, which ensures several times longer usage of the filter cartridge. However, this requires the use of a special air filter design, and additional experimental tests in this area.

4) With the increase of dust mass retained on the filter cartridge (increase in the dust mass loading $\mathrm{k}_{\mathrm{m}}$ of the cartridge), the filtering efficiency of the tested cartridges increases dramatically during the initial period, however a more intense increase is observed for the insert with the nanofiber addition. The filter insert with the nanofiber layer achieves the initial filtration efficiency $\varphi_{\mathrm{w} 0}=99.34 \%$. Such filtration efficiency value, cellulose cartridge reaches when the dust mass loading $\mathrm{k}_{\mathrm{m}}=53$ $\mathrm{g} / \mathrm{m}^{2}$. The initial filtration efficiency of this cartridge is $\varphi_{\mathrm{w} 0}=96.54 \%$.

5) The filtration cartridge with nanofiber addition in the whole range of work, achieves the filtration performance (maximum size of dust grains $d_{z \max }$ ) in the range of $\mathrm{d}_{\mathrm{z} 1 \mathrm{max}}=2.7-5.5 \mu \mathrm{m}$. Filtration performance of the cellulose cartridge in the initial period reaches the value of $\mathrm{d}_{\mathrm{z} 1 \max }=2.7-5.5 \mu \mathrm{m}$, and after obtaining almost $50 \%$ of the total working time of the cartridge, the accuracy is at the level of $\mathrm{d}_{\mathrm{z} 2 \max }=4.7 \mu \mathrm{m}$. Such air with mineral dust sucked into car cylinder can accelerate its usage. 
6) Flow resistance increase intensity of the inserts with an additional nanofiber layer is significantly higher, therefore the permissible value of $\Delta \mathrm{p}_{\mathrm{wdop}}=4 \mathrm{kPa}$ is reached much faster. This increases filter cartridges exchange frequency, and thus increases operating costs.

\section{Nomenclature}

BDC bottom dead center

P-R-C piston-piston rings-cylinder

UDC upper dead center

\section{Bibliography}

[1] AVIS, M. Particles: friend or foe? understanding the value of particles in oil analysis. Machinery Lubrication. 2012, 6.

[2] BARRIS, M.A. Total Filtration ${ }^{\mathrm{TM}}$ : The influence of filter selection on engine wear emissions, and performance. 1995. SAE Technical Paper 952557.

[3] Diesel engine air filtration, Materiały informacyjne firmy PALL Corporation. 2004, USA.

[4] BUGLI, N. Automotive engine air cleaners - performance trends. SAE Technical Paper 2001-01-1356.

[5] DURST, M., KLEIN, G., MOSER, N. Filtration in Fahrzeugen. Mann+Hummel GMBH, Ludwigsburg, Germany 2005.

[6] DZIUBAK, T. Problems of dust removal from multicyclones of engine air cleaners in cross-country motor vehicles, The Archives of Automotive Engineering. 2017, 76(2), 37-62.

[7] DZIUBAK, T. Operating fluids contaminantions and their effect on the wear of elements of a motor vehicles combustion engine. The Archives of Automotive Engineering Archiwum Motoryzacji. 2016, 72(2), 93-122.

[8] DZIUBAK, T., SZWEDKOWICZ, S. Operating properties of non-woven fabric panel filters for internal combustion engine inlet air in single and two-stage filtration systems. Eksploatacja i Niezawodność - Maintenance and Reliability. 2015, 17(4), 519-527.

[9] ERDMANNSDÖRFER, H. Lesttingmoglichkeiten von Papierfiltern zur Reinigung der Ansaugluft von Diselmotoren. MTZ. 1971, 32, 123-131.

[10] FITCH, J. Clean oil reduces engine fuel consumption. Practicing Oil Analysis. 2002, 11/12.

[11] GEORGE, J., FORNA, R., CRAVERO, T. Air filtration with fine polymeric fibers. 16-th Annual Technical Conference and Exposition 2003 Technical Sessions Papers, RenoNevada, June 17-20, 2003.

[12] GRAFE, T., GOGINS, M., BARRIS, M. et al. Nanofibers in filtration applications in transportation. Filtration 2001 International Conference and Exposition, Chicago, December 3-5, 2001.

[13] GRAHAM, K., OUYANG M., RAETHER T. et al. Polymeric nanofibers in air filtration applications, 5th Annual
Technical Conference \& Expo of the American Filtration \& Separations Society, Galveston, Texas, April 9-12, 2002.

[14] HEIKKILÄ, P., SIPILÄ, A., PELTOLA, M., HARLIN, A. Electrospun PA-66 Coating on Textile Surfaces, Institute of Fibre Materials Science, Tampere University of Technology, P.O. Box 589, FIN-33101, Tampere, Finland. 2007, 864870.

[15] JAROSZCZYK, T., PETRIK, S., DONAHUE, K. Recent development in heavy duty engine air filtration and the role of nanofiber filter media. Journal of KONES Powertrain and Transport. 2009, 16(4), 207-216.

[16] JAROSZCZYK, T., FALLON, S. L., SCHWARTZ, S.W. Development of high dust capacity, high efficiency engine air filter with nanofibers. Journal of KONES Powertrain and Transport. 2008, 15(3), 215-224.

[17] KHAJAVI, R., ABBASIPOUR, M., BAHADOR, A. Electrospun biodegradable nanofibers scaffolds for bone tissue engineering. Journal Applied Polymer Science. 2016, 133(3), 42883.

[18] KOSZAŁKA, G., SUCHECKI, A. Changes in performance and wear of small diesel engine during durability test. Combustion Engines. 2015, 162(3), 34-40.

[19] LI, D., XIA, Y. Electrospinning of nanofibers: reinventing the wheel? Advanced Materials. 2004, 16(14), 1151-1170.

[20] LO, L.-M., CHEN, D.-R., PUI, D.Y.H. Experimental study of pleated fabric cartridges in a pulse-jet cleaned dust collector. Powder Technology. 2010, 197, 141-149.

[21] PN-ISO 5011. Filtry powietrza do silników spalinowych i sprężarek. PKNM, 1994.

[22] TAUFKIRCH, G., MAYR, G. Papierluftfilter für Motoren in Nutzfahrzeugen, MTZ. 1984, 45(3), 95-105.

[23] TRAUTMANN, P., PELZ, A., DURST, M., MOSER, N. High performance nanofibre coated filter media for engine intake. Air AFS 2005 Conference and Expo, April 10-13, 2005.

[24] http://www.cottonbangladesh.com/January2009/ElectroSpin ning.htm [14.12.2017].

[25] http://www.cottonbangladesh.com/January2009/ElectroSpin ning.htm [09.10.2018].

Tadeusz Dziubak, DSc., DEng. - Faculty of Mechanics Military University of Technology, Warsaw, Poland.

e-mail: tadeusz.dziubak@wat.edu.pl 